Neth. J. Pl. Path. 97 (1991) 87-103

\title{
Simulation of damage in winter wheat caused by the grain aphid Sitobion avenae. 3. Calculation of damage at various attainable yield levels
}

\author{
W.A.H. ROSSING
}

Department of Theoretical Production Ecology, Wageningen Agricultural University, P.O. Box 430, $6700 \mathrm{AK}$ Wageningen, the Netherlands

Accepted 30 October 1990

\begin{abstract}
A dynamic, process-based simulation model is used to evaluate the effect of injury by Sitobion avenae $\mathrm{F}$. on yield of winter wheat at a range of attainable yield levels. The attainable yield is defined as the yield in the absence of pests and diseases, at the prevailing temperature and radiation and the available amount of soil nitrogen. Water limitation is not taken into account. Only the period from flowering to ripeness is considered. Aphid infestation intensity is expressed in aphid-days, the integral of aphid density $\left(t_{i l l e r}{ }^{-1}\right)$ over time (day). The calculations show that damage per aphid-day decreases from flowering to ripeness because damage caused by honeydew decreases with advancing crop development stage while damage caused by aphid feeding is about constant. Damage per aphid-day during a particular period of crop development increases in a nearly linear fashion with the attainable yield level. At attainable yield levels over approximately $9000 \mathrm{~kg} \mathrm{ha}^{-1}$ and until crop development stage early milky ripe (DC 73), however, damage per aphid-day increases at a higher rate with the attainable yield level as compared to lower yield levels. The crop-physiological causes are discussed.

Regression models are constructed that relate simulated aphid damage both during various periods of crop development and averaged over the entire post-anthesis phase, to the simulated attainable yield level. The accuracy of these simulation-based regression models and five published models of damage in winter wheat caused by $S$. avenae is evaluated using 21 data sets, obtained in experiments carried out between 1973 and 1984 in the Netherlands. Attention is focussed on two aspects of model accuracy: the agreement between predicted and measured damage and the size of the error in model predictions. In both aspects the simulation-based regression models are as good as the best published empirical models.
\end{abstract}

Additional keywords: regression model, single point model, multiple point model, prediction, validation, honeydew.

\section{Introduction}

Cereal aphids have been an occasional pest in west European wheat cultivation only since the early seventies. Their increased economic importance has been attributed to changes in farm practice, especially high nitrogen fertilizer rates and fungicide inputs (Carter et al., 1982). After evaluation of a large body of field experiments Rabbinge et al. (1983) hypothesized that aphids cause relatively more damage at higher attainable yield levels, i.e. levels of yield in the absence of aphids and other crop growth 
reducing factors (Zadoks and Schein, 1979). Direct evidence for this hypothesis is difficult to obtain as it requires many experiments over a range of crop production situations.

In this paper, attention is focussed on Sitobion avenae F., the grain aphid, which constitutes the most abundant cereal aphid species in the Netherlands. In an earlier paper (Rossing, 1991), a systems approach (de Wit and Goudriaan, 1978; Rabbinge et al., 1989) was taken to quantify damage by $S$. avenae in winter wheat. A simulation model of growth and development of winter wheat from flowering to ripeness was combined with a model of injury by $S$. avenae. In these models, information on the processes involved (Groot, 1987; Van Keulen and Seligman, 1987; Rossing and Van de Wiel, 1990) was integrated to explain winter wheat yield, given the available amount of soil nitrogen, the prevailing weather and the observed aphid population. Water limitation was not taken into account. Evaluation of the crop growth model was carried out for attainable winter wheat yields ranging from $5000 \mathrm{~kg} \mathrm{ha}^{-1}$ to $10000 \mathrm{~kg}$ $\mathrm{ha}^{-1}$. The injury model was evaluated at the higher yield levels only due to lack of data at other yield levels (Rossing, 1991).

In this study, the winter wheat - S. avenae model is used to calculate the effect of a grain aphid infestation on grain yield at different attainable yield levels. Due to the explanatory nature of the model, differences in effects of aphid injury on yield can be attributed to their crop-physiological causes. Next, the results of the simulation study are summarized in regression models suitable for use in decision support systems like EPIPRE (Drenth et al., 1989). Finally, the accuracy of these regression models is compared to the accuracy of a number of published models of damage by $S$. avenae in winter wheat, using a set of independent field data.

\section{Materials and methods}

Weights in this paper are based on a grain moisture content of $16 \%$. Crop development is expressed in Decimal Code (DC) (Zadoks et al., 1974).

\section{Simulation of damage at various attainable yield levels}

Grain yield in absence and presence of a $S$. avenae population is calculated using a computer model described previously (Rossing, 1991). With this model, growth and development of winter wheat during the post-anthesis phase, i.e. the period from flowering to ripeness, is simulated as a function of injury by $S$. avenae. Crop analysis data from nine experiments are used to initialize the winter wheat model at anthesis. The amount of soil nitrogen available from anthesis to ripeness is input for the model. In this way, nine different attainable yield levels are simulated using realistic initial crop conditions. All data have been collected in experiments designed to evaluate the effect of the rate of nitrogen fertilizer application on crop production. Six of the data sets used, BOUWING84, EEST83, EEST84, PAGV1, PAGV2 and PAGV3, have been described in an earlier paper (Rossing, 1991). Three additional data sets, HELECINE1, HELECINE2 and HELECINE3, pertain to experiments carried out in north Belgium (Anon., 1984; Anon., 1985). General information on these experiments is given in Table 1. Temperature and radiation data used as model input are 33 year daily averages of Wageningen, the Netherlands. The duration of crop development from flowering to ripeness is fixed on 47 days (Table 2). Running the crop growth simulation model 
Table 1. General information on the data sets HELECINE1, HELECINE2 and HELECINE3 used to initialize the winter wheat crop model.

\begin{tabular}{|c|c|c|c|}
\hline & HELECINE1 & HELECINE2 & HELECINE3 \\
\hline Location & Helecine, Belgium & Helecine, Belgium & Helecine, Belgium \\
\hline Wheat variety & Corin & Corin & Corin \\
\hline Grain yield $\left(\mathrm{kg} \mathrm{ha}^{-1}\right)$ & 6151 & 5800 & 5077 \\
\hline Previous crop & sugar beets & sugar beets & sugar beets \\
\hline Sowing date & 10 Nov 1984 & 10 Nov 1983 & 10 Nov 1983 \\
\hline Flowering date & 7 June 1985 & 13 June 1984 & 13 June 1984 \\
\hline Harvest date & 12 August 1985 & 22 August 1984 & 22 August 1984 \\
\hline Row spacing $(\mathrm{cm})$ & 15 & 15 & 15 \\
\hline Sowing density $\left(\mathrm{kg} \mathrm{ha}^{-1}\right)$ & 160 & $?$ & $?$ \\
\hline Total $N\left(\mathrm{~kg} \mathrm{ha}^{-1}\right)$ & 71 & 154 & 86 \\
\hline Growth regulator & no & yes & yes \\
\hline Protective chemicals ${ }^{a}$ & $\mathrm{H}, \mathrm{F}$ & $\mathrm{H}, \mathrm{F}$ & $\mathrm{H}, \mathrm{F}$ \\
\hline
\end{tabular}

${ }^{a} \mathrm{H}=$ herbicide, $\mathrm{F}=$ fungicide.

with the various initial crop and soil conditions and the same set of values for temperature, radiation and crop development duration results in attainable grain yields ranging from $3500 \mathrm{~kg} \mathrm{ha}^{-1}$ to $10000 \mathrm{~kg} \mathrm{ha}^{-1}$.

The simulation model accounts for two components of aphid injury: aphid feeding on the phloem sap and reduction of net photosynthesis by honeydew. Aphid feeding is assumed to cause a decrease of the rate of carbohydrate and nitrogen accumulation in the grains equal to the rate of uptake of these components by the aphids. This assumption which has been referred to as hypothesis IV previously, appears the most appropriate for describing aphid feeding in view of experimental evidence (Rossing, 1991). Honeydew contributes to damage as it increases the rate of maintenance respiration and decreases the rate of carbon dioxide assimilation at light saturation. The

Table 2. Time course of crop development and aphid population density used in the simulation model to calculate aphid damage at various attainable yield levels.

\begin{tabular}{llcc}
\hline $\begin{array}{l}\text { Day of } \\
\text { the year }\end{array}$ & $\begin{array}{l}\text { Crop development } \\
\text { stage }\end{array}$ & $\begin{array}{l}\text { Aphid density } \\
\left(\text { tiller }^{-1}\right)\end{array}$ & $\begin{array}{c}\text { Aphid index } \\
\text { (day tiller }\end{array}$ \\
173 & 60 & 0.25 & 0 \\
176 & 65 & 0.40 & 0.90 \\
179 & 69 & 0.56 & 2.26 \\
181 & 71 & 0.65 & 3.42 \\
186 & 73 & 1.65 & 8.17 \\
193 & 75 & 5.86 & 30.70 \\
201 & 77 & 11.75 & 123.77 \\
209 & 83 & 0.00 & 157.37 \\
220 & 90 & 0.00 & 157.37 \\
\hline
\end{tabular}

Neth. J. Pl. Path. 97 (1991) 
$§$ Table 3. Models evaluated with respect to their accuracy in predicting cereal aphid damage in winter wheat.

\begin{tabular}{|c|c|c|c|c|c|}
\hline $\begin{array}{l}\text { Num- } \\
\text { ber }\end{array}$ & Source & Model & & & Model type \\
\hline 1. & Vereijken (1979) & yield loss $\left(\mathrm{kg} \mathrm{ha}^{-1}\right)$ & $=15.51+10.97$ & $\times\left(\right.$ peak aphids ear $\left.{ }^{-1}\right)$ & single point \\
\hline 2. & Rabbinge \& Mantel (1981) & yield loss $\left(\mathrm{kg} \mathrm{ha}^{-1}\right)$ & $=-79.9+17.2$ & $\times$ (peak aphids tiller $^{-1}$ ) & single point \\
\hline 3. & Rabbinge \& Mantel (1981) & yield loss $\left(\mathrm{kg} \mathrm{ha}^{-1}\right)$ & $\doteq \quad 66.7+24.3$ & $\times\left(\right.$ peak aphids ear $\left.{ }^{-1}\right)$ & single point \\
\hline 4. & Entwistle \& Dixon (1987) & percent yield loss & $=0.951+0.273$ & $\times$ (peak $S$. avenae tiller $^{-1}$ ) & single point \\
\hline 5. & Rossing (this paper) & yield loss $\left(\mathrm{kg} \mathrm{ha}^{-1}\right)$ & $=[-6.18+2.03$ & $\times \log _{10}($ attainable yield $\left.)\right] \times$ aphid-index & single point \\
\hline \multirow[t]{7}{*}{6.} & \multirow[t]{7}{*}{ Entwistle \& Dixon (1987) } & $\begin{array}{l}\text { crop development } \\
\text { period }\end{array}$ & \multicolumn{2}{|l|}{$\begin{array}{l}\text { percent damage } \\
\text { per aphid-unit day }\end{array}$} & multiple point \\
\hline & & $<53$ & 0.075 & & \\
\hline & & $\begin{array}{ll}53 & -68.9\end{array}$ & 0.205 & & \\
\hline & & $69-70.9$ & 0.075 & & \\
\hline & & $71-73$ & 0.056 & & \\
\hline & & $73.1-76.9$ & 0.037 & & \\
\hline & & $\geq 77$ & 0.012 & & \\
\hline 7. & Rossing (this paper) & See Table 5 & & & multiple point \\
\hline
\end{tabular}


change in these photosynthesis parameters is a linear function of the amount of daily intercepted honeydew and increases with time at a constant rate until a maximum is reached 15 days after honeydew interception. In the model, no response is allowed above the maximum values measured in experiments, i.e. $35 \%$ increase of the rate of maintenance respiration and $24 \%$ decrease of the rate of carbon dioxide assimilation at light saturation. A more detailed description of the model is given elsewhere (Rossing, 1991).

The time course of aphid density introduced into the model is shown in Table 2. No distinction is made between various developmental classes. The aphids feed on the ears only. The simulation model is run repeatedly with the same weather data and initial conditions but with the aphid population density set to zero at subsequently earlier crop development stages. Thus, the average effect of aphids on grain yield can be calculated for different periods of crop development. In total, six periods of crop development are distinguished. The results are expressed per aphid-day by dividing damage incurred during a particular period of crop development by the concomitant integral of aphid density (tiller ${ }^{-1}$ ) over time. This integral, the aphid-index, is a commonly used measure of infestation intensity (Rautapää, 1966).

\section{Construction of simulation-based regression models}

The results of the simulation runs are summarized in regression models which relate simulated damage per aphid-day to simulated attainable yield, both averaged over the entire post-anthesis phase and for each of the six periods of crop development separately. Three types of regression models are fitted: a linear model, an exponential model and a logarithmic model. Choice of these models is suggested by visual inspection of the data. Least-squares estimates of the parameters of the regression models are calculated using a statistical software package (SAS, 1985).

\section{Accuracy of the simulation-based models in comparison with other models}

The regression models with the best fit to the simulation results are hypothesized to give an, on average, accurate description of damage by $S$. avenae for the various periods of crop development. To test this hypothesis and to compare the accuracy of these simulation-based regression models to the accuracy of empirical regression models for S. avenae damage by Vereijken (1979), Rabbinge and Mantel (1981) and Entwistle and Dixon (1987), the predictions of each model are compared to damage measured in field experiments. An overview of the various models is given in Table 3 . For the evaluation of the models, data sets from 21 field experiments carried out in the Netherlands are available, 19 of which have been used previously by Rabbinge and Mantel (1981). The two additional data sets have been described by Rossing and Van de Wiel (1990). Care is taken not to use the same data for model evaluation as have been used in the development of the models.

The experimental data used for evaluation of the models consist of aphid density $\left(\right.$ tiller $\left.^{-1}\right)$ sampled at approximately weekly intervals, all instars lumped, the development stage of the crop and the mean final yield of infested and uninfested plots. Aphid-days are calculated as the integral of aphid density over time, using linear interpolation to calculate aphid density between data points. Aphid-unit days are calculated according to the procedure described by Wratten et al. (1979). In this procedure, the densities of the age-cohorts L1-L3, L4 and adults are weighted to account for

Neth. J. Pl. Path. 97 (1991) 
Table 4. Multiplication factors used for the conversion of aphid-days into aphid-unit days, calculated using data of Mantel et al. (1982) to estimate the age distribution of the aphid population. One aphid-unit is equivalent to one adult, one L4 or three L1-L3 (Wratten et al., 1979).

\begin{tabular}{lll}
\hline $\begin{array}{l}\text { Crop development } \\
\text { stage }\end{array}$ & $\begin{array}{l}\text { Estimated } \\
\text { fraction L1-L3 }\end{array}$ & $\begin{array}{l}\text { Multiplication } \\
\text { factor }\end{array}$ \\
$<60$ & 0.74 & 0.51 \\
60 & 0.74 & 0.51 \\
70 & 0.80 & 0.47 \\
77 & 0.60 & 0.60 \\
$>77$ & 0.60 & 0.60 \\
\hline
\end{tabular}

instar-related differences in feeding rate. Since in the available data sets instars are not distinguished, data of Mantel et al. (1982) are used to estimate the age distribution of the aphid population as a function of crop development stage. The factors used for conversion of aphid-days into aphid-unit days are shown in Table 4. The figures before DC 60 and after DC 77 are extrapolations. Between data points, the value of the multiplication factor is calculated by linear interpolation. A summary of the data sets is given in Appendix 1. Where aphid density per ear is required as model input, $84 \%$ of the aphid population on a tiller is assumed to occur on the ear (Entwistle and Dixon, 1987).

Two aspects of model accuracy are evaluated. Firstly, the predictions of a regression model are compared to measured damage and statistically tested for systematic errors. This analysis assesses whether the model's representation of the real world system is demonstrably wrong. Penning de Vries (1977) referred to this aspect of accuracy as the truthfulness of a model. Secondly, the distributions of the prediction error, i.e. the difference between measured and predicted values, of the various models are evaluated using a statistical selection procedure. This aspect of accuracy may be called the usefulness of a model as in the context of decision making it is of more interest than the truthfulness.

The truthfulness of the regression models is evaluated by testing the prediction error for both systematic over- or underprediction and trend as a function of measured damage. Three statistical tests are used: an F-test in which both errors are evaluated simultaneously, and two non-parametric tests for detection of each error separately. In the F-test, the hypothesis is tested that the prediction error has expectation zero, whereas the alternative hypothesis allows for bias in the expected prediction error which is a linear function of measured damage. When the data sets are independent and representative for situations in which the model is to be used, the $f$-statistic is calculated as

$$
f=\frac{\left(R S S_{0}-R S S_{1}\right) / 2}{R S S_{1} /(n-2)}, \quad f \sim F_{n-2}^{2}
$$

where $R S S_{0}$ : residual sum of squares under the null hypothesis; $R S S_{1}$ : residual sum of squares under the alternative hypothesis; $n$ : number of observations. In addition, Wilcoxon's signed rank test is used to detect systematic over- or underprediction by 
evaluating the null hypothesis that the predicted damage and the measured damage originate from the same distribution. Spearman's rank correlation test is used to assess trend in the prediction error by evaluating the null hypothesis that there is no rank correlation between the prediction error and measured damage (Snedecor and Cochran, 1980).

The accuracy of the regression models is evaluated by means of a nonparametric selection procedure (Gibbons et al., 1977). The procedure involves ordering the frequency distributions of the absolute value of the prediction error of the models on the basis of the value of a sample quantile. Here, the $50 \%$ quantile and the $75 \%$ quantile are used as ordering criteria. The $50 \%$ quantile represents the median accuracy of the model, while the $75 \%$ quantile in combination with the $50 \%$ quantile yields an indication of the variability in accuracy.

\section{Results and discussion}

Simulated damage at various attainable yield levels

Simulated damage per aphid-day averaged over the post-anthesis phase is shown in Fig. 1 for various simulated attainable yield levels. Average damage per aphid-day increases with the attainable yield level but levels off at high yield levels.

A more detailed analysis is presented in Fig. 2 where simulated damage per aphidday caused during various periods of crop development is shown as a function of simulated attainable yield level. Aphids present before mid-flowering (DC 65) cause the largest damage per aphid-day at all attainable yield levels. Simulated damage per aphid-day decreases with advancing crop development stage because damage caused by honeydew decreases (Fig. 3). Damage caused by aphid feeding remains approximately constant. Honeydew damage is larger at earlier crop development stages because the simulated effects of an intercepted amount of honeydew accumulate with time.

Per period of crop development, simulated damage per aphid-day increases approximately linearly with the simulated attainable yield level except for the three highest yield levels where simulated damage exceeds the linear trend between DC 60 and DC 73 (Fig. 2). The relatively large damage between DC 60 and DC 73 at attain-

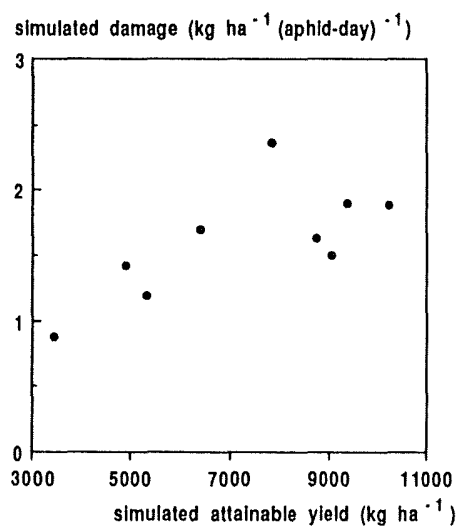

Fig. 1. Simulated damage per aphid-day averaged over the post-anthesis phase at various attainable yield levels. The duration of the post-anthesis phase is fixed on 47 days.

Neth. J. Pl. Path. 97 (1991) 
simulated damage (kg ha-1 (aphid-day) ${ }^{-1}$ )
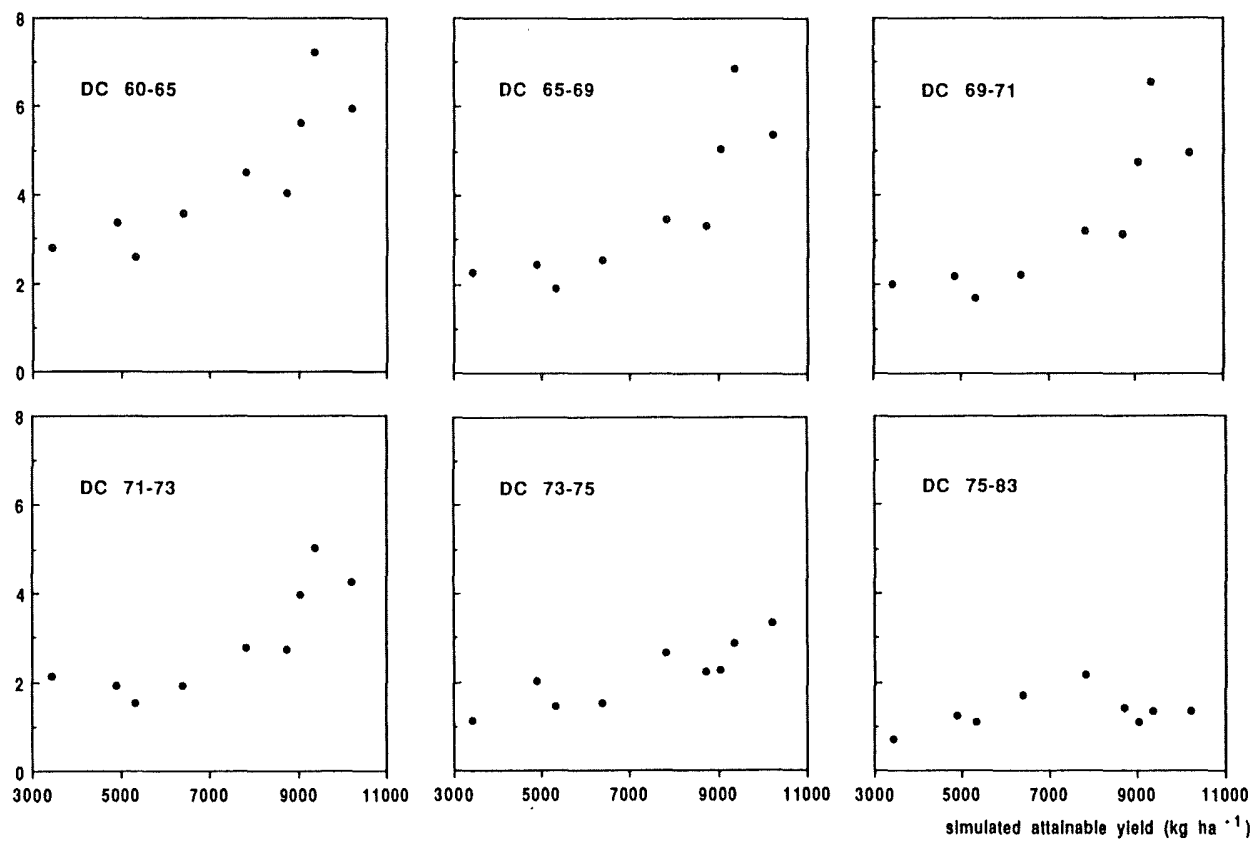

Fig. 2. Simulated damage per aphid-day caused during six periods of crop development at various attainable yield levels.

able yield levels over $9000 \mathrm{~kg} \mathrm{ha}^{-1}$ is due to the large values of leaf area index in highyielding crops. At large values of leaf area index the marginal contribution of green leaf area to yield is small, due to mutual shading, whereas the damage resulting from the effect of honeydew on the rate of maintenance respiration (up to $35 \%$ increase) is fully proportional to leaf area index. The effect of honeydew on the maximum rate of carbon dioxide assimilation (up to $24 \%$ decrease) is proportional to leaf area index

simulated damage $\left(\mathrm{kg} \mathrm{ha}^{-1}\right.$ (aphid-day) $\left.{ }^{-1}\right)$

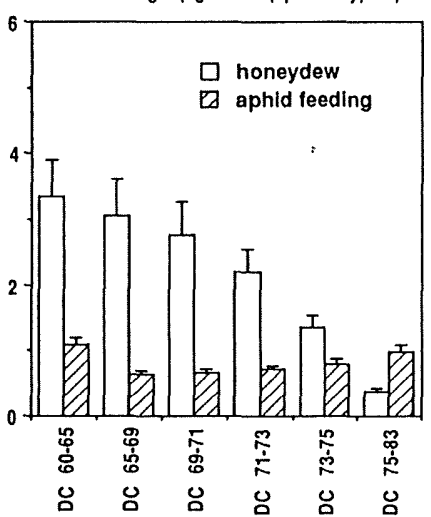

94
Fig. 3. Simulated damage by $S$. avenae due to honeydew and aphid feeding, respectively, during six periods of crop development, averaged over the nine attainable yield levels. The vertical bars represent standard errors. 


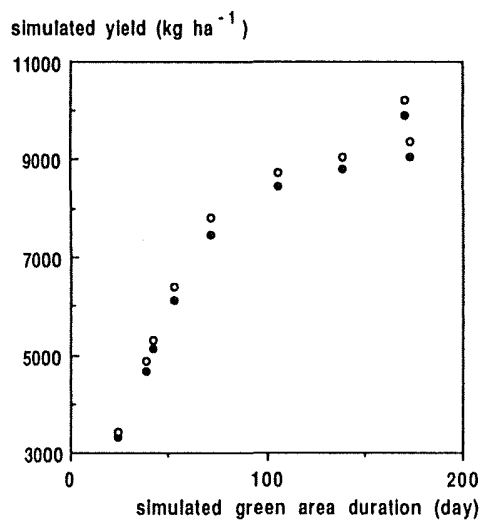

Fig. 4. Simulated yield and simulated green area duration in the absence (o) and presence $(\bullet)$ of an aphid infestation. The duration of the post-anthesis phase is fixed on 47 days.
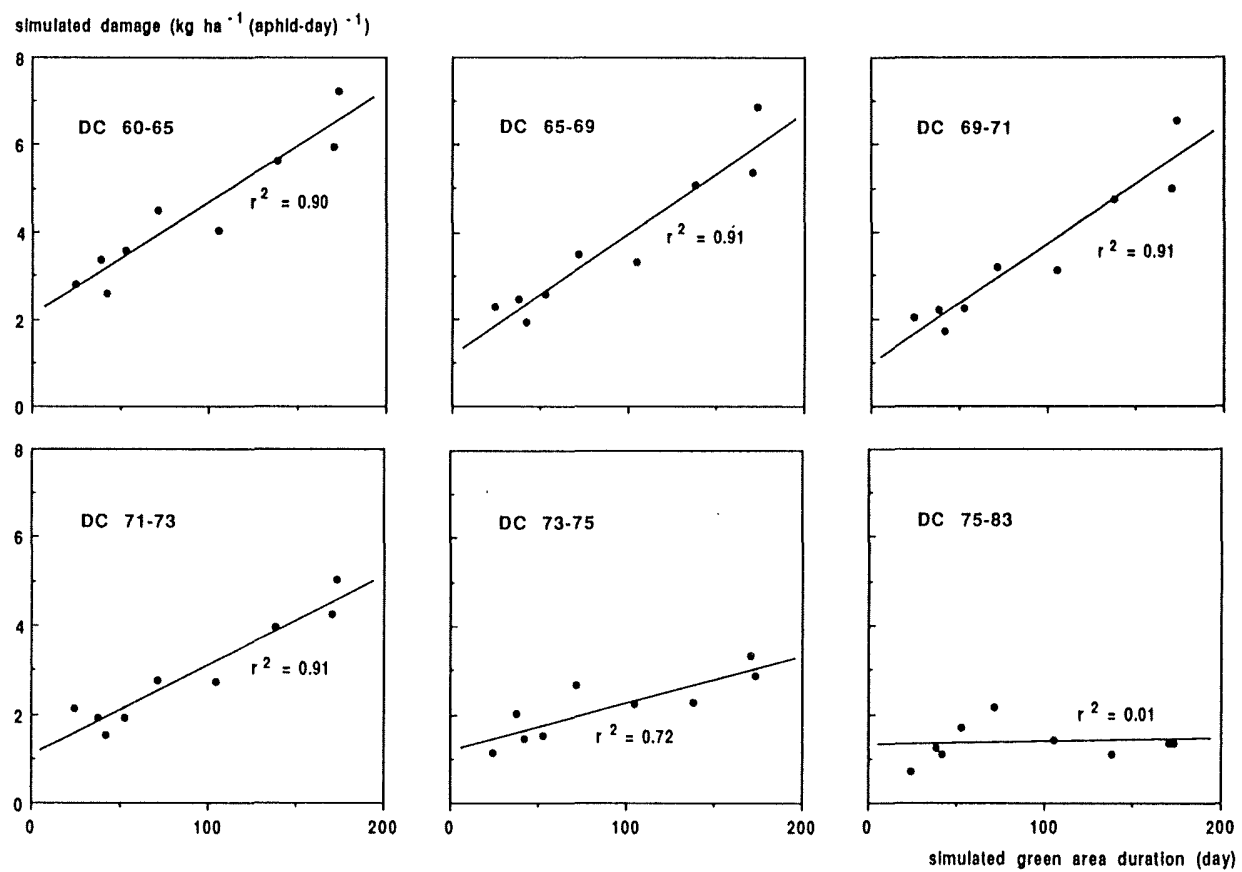

Fig. 5. Simulated damage per aphid-day caused during six periods of crop development at various simulated green area duration. In the figures the coefficient of deter mination $r^{2}$ is shown in combination with the line minimizing the residual sum of squares.

at saturating light intensities. The dissimilar effects of additional green leaf area on yield and damage are illustrated in Fig. 4 and Fig. 5, respectively, where green area duration, the integral of leaf area index over time, is used to characterize the leaf area dynamics. The marginal contribution of green area duration to simulated yield decreases at high yield levels (Fig. 4), whereas simulated aphid damage increases in proportion to green area duration between DC 60 and DC 73 (Fig. 5). After DC 73

Neth. J. Pl. Path. 97 (1991) 
simulated damage is increasingly due to aphid feeding (Fig. 3) as the time remaining until cessation of grain filling (approximately DC 83) is too short for accumulation of substantial honeydew damage. Since simulated damage by aphid feeding is largely independent of leaf area index, the correlation between simulated aphid damage and green area duration is lower after DC 73 as compared with earlier stages (Fig. 5).

Variation in simulated response of the crop to the aphid population is due to differences in crop characteristics among the data sets used to initialize the model at flowering. The crop condition at flowering reflects the effect of variable factors like temperature, radiation and nitrogen and water availability before flowering. For instance, the data sets EEST84, BOUWING84 and PAGV3 are similar with respect to nitrogen gift and simulated attainable yield. However, the simulated damage for EEST84 is greater than for the other two data sets due to the larger leaf area index and the smaller amount of reserves for EEST84 as compared to BOUWING84 and PAGV3.

The duration of the post-anthesis phase affects damage because the development of the aphid population is significantly synchronized with crop development (Carter et al., 1982) whereas the effects of aphid feeding and honeydew are functions of time. Consequently, a cool summer will result in a longer post-anthesis phase and more damage by a particular aphid infestation than a hot summer with a shorter postanthesis phase. While the model has been run with a post-anthesis phase of 47 days, the real post-anthesis phase in the crop data sets varies from 40 to 57 days. The quantitative consequences of a different duration of the post-anthesis phase depend upon the duration of the various periods of crop development in combination with the dynamics of the aphid population during these periods. Early during the post-anthesis phase the crop is more sensitive to aphids (cf. Fig. 2) while aphid densities are usually low. Later, high densities may cause large damage in spite of the crop being less sensitive. In Fig. 6, simulated average damage per aphid-day for a 57 day post-anthesis phase is compared to that for a 47 day post-anthesis phase, assuming the duration of all crop development periods to be increased with a factor 57/47. The aphid population is introduced as a function of crop development stage according to the data in Table 2, resulting in an aphid load of 164 aphid-days for the 57 day post-anthesis phase. The protracted post-anthesis phase results in both higher simulated attainable yield $\left(0-475 \mathrm{~kg} \mathrm{ha}^{-1}\right)$ and higher simulated average damage $\left(0.1-0.7 \mathrm{~kg} \mathrm{ha}^{-1}\right.$ (aphidday $)^{-1}$ ). Differences with the 47 day post-anthesis phase are most pronounced at

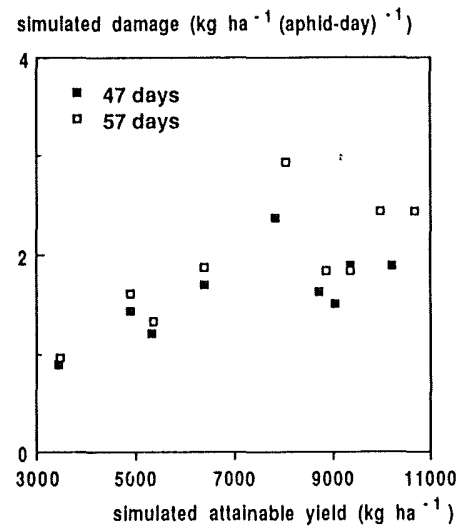

96
Fig. 6. Simulated average damage per aphid-day $(\mathrm{kg}$ $\mathrm{ha}^{-1}$ (aphid-day) $\left.)^{-1}\right)$ at nine simulated attainable yield levels $\left(\mathrm{kg} \mathrm{ha}^{-1}\right)$ and a post-anthesis phase of $47(\mathbf{)})$ and 57 days (ㅁ), respectively.

Neth. J. Pl. Path. 97 (1991) 
Table 5. Regression models best fitting the relation between simulated damage per aphid-day $\left(y\right.$, in $\mathrm{kg} \mathrm{ha}^{-1}$ (aphid-day) $\left.{ }^{-1}\right)$ and simulated attainable yield $\left(x\right.$, in $\left.\mathrm{kg} \mathrm{ha}^{-1}\right)$. The statistic $r^{2}$ represents the fraction of the variation in $y$ accounted for by the model. The residual error has the same dimension as $y$.

\begin{tabular}{llll}
\hline $\begin{array}{l}\text { Crop } \\
\text { development } \\
\text { period }\end{array}$ & Model & $r^{2}$ & $\begin{array}{l}\text { Residual } \\
\text { error }\end{array}$ \\
$60-65$ & $y=1.47 \times 10^{6.28 \times 10^{-4} x}$ & 0.77 & 0.81 \\
$65-69$ & $y=0.85 \times 10^{8.28 \times 10^{-5} x}$ & 0.74 & 0.92 \\
$69-71$ & $y=0.71 \times 10^{8.77 \times 10^{-5} x}$ & 0.74 & 0.90 \\
$71-73$ & $y=0.75 \times 10^{7.70 \times 10^{-5} x}$ & 0.75 & 0.65 \\
$73-75$ & $y=0.77 \times 10^{5.91 \times 10^{-5} x}$ & 0.79 & 0.35 \\
$75-83$ & $y=-3.27+1.20 \times \log _{10}(x)$ & 0.22 & 0.39 \\
$60-83$ & $y=-6.18+2.03 \times \log _{10}(x)$ & 0.56 & 0.31 \\
\hline
\end{tabular}

higher yield levels. Total damage increases marginally $\left(10-130 \mathrm{~kg} \mathrm{ha}^{-1}\right)$.

\section{Construction of simulation-based regression models}

Regression of simulated damage per aphid-day during different periods of crop development on simulated yield of an uninfested crop shows that, depending on the period of crop development, the best fit (highest $r^{2}$ and smallest residual error) is obtained five times with an exponential model and two times with a logarithmic model. Table 5 shows the best-fitting models.

Accuracy of the simulation-based models in comparison with other models

The seven models for damage by $S$. avenae listed in Table 3 belong to two groups of prediction models: single point (models 1 to 5) and multiple point (models 6 and 7) (Zadoks and Schein, 1979). The single point models use a single characteristic of the aphid population curve to predict damage. In models 1 to 4 peak aphid density is used as the characteristic quantity, in model 5 aphid density integrated over time (aphidindex). The multiple point models fractionate the aphid population curve and calculate the contribution of each fraction to damage. In model 6 and 7 the fractions represent the aphid-index during various periods of crop development. In Fig. 7 the relation between predicted damage and damage measured in field experiments is shown for each of the models, using the data sets described in Appendix 1.

Evaluation of the 'truthfulness' of the seven models shows that all single point models based on peak aphid density (models 1 to 4) deviate significantly from measured values (F-test, $p<0.01$, Table 6 ). For these models, Spearman's rank correlation test indicates a significant trend in the prediction error while Wilcoxon's signed rank test points to significant bias in models 1 and $2(p<0.01)$. For the single point model based on aphid index (model 5) a significant trend in the prediction error is found $(p<0.05)$, whereas neither the F-test nor Wilcoxon's signed rank test detects significant deviations from reality. Neither of the models in which damage per aphidday is a function of crop development stage (models 6 and 7) is rejected by any of the three statistical tests. 

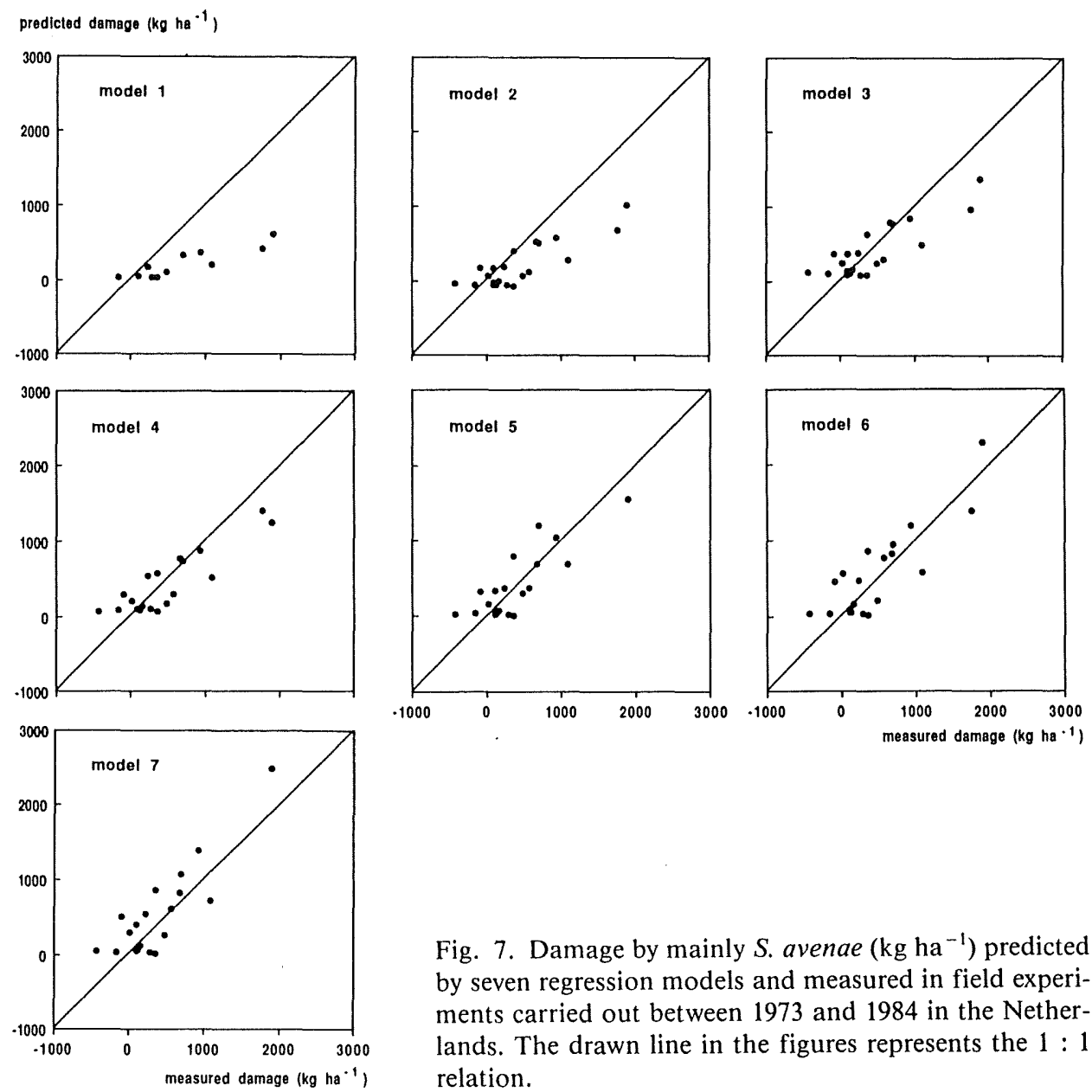

Fig. 7. Damage by mainly $S$. avenae $\left(\mathrm{kg} \mathrm{ha}^{-1}\right)$ predicted by seven regression models and measured in field experiments carried out between 1973 and 1984 in the Netherlands. The drawn line in the figures represents the $1: 1$ relation.

Table 6. Statistical evaluation of the truthfulness of seven regression models for cereal aphid damage in winter wheat, using $n$ datasets from the Netherlands. A description of the models is given in Table 3. The variables $f, Z_{\mathrm{c}}$ and $r_{\mathrm{s}}$ represent the statistics of the F-test, Wilcoxon's signed rank test and Spearman's rank correlation test, respectively.

\begin{tabular}{llccc}
\hline Model & $n$ & $f$ & $Z_{\mathrm{c}}$ & $r_{\mathrm{s}}$ \\
1 & 11 & $234.30^{* *}$ & $-2.67^{* *}$ & $-0.98^{* *}$ \\
2 & 21 & $52.90^{* *}$ & $-2.66^{* *}$ & $-0.67^{* *}$ \\
3 & 21 & $17.09^{* *}$ & -0.26 & $-0.67^{* *}$ \\
4 & 20 & $19.63^{* *}$ & -0.23 & $-0.74^{* *}$ \\
5 & 20 & 2.88 & -0.52 & $-0.48^{*}$ \\
6 & 20 & 1.51 & -1.16 & -0.30 \\
7 & 20 & 1.98 & -1.76 & -0.07 \\
\hline
\end{tabular}

$* p<0.05$.

** $p<0.01$. 
Entwistle and Dixon (1987) attribute the lack of correspondence between predictions of damage based on peak aphid density and reality to differences in the distribution of aphids over the plant and to the importance of the duration as well as the size of the infestation. The results presented here do not support the first supposition as the distribution of aphids over the plant is not accounted for in models 6 and 7 while their predictions do not differ significantly from reality. The presumed importance of the duration and the size of the population implies that aphid-index should be a more useful characteristic for predicting damage than peak aphid density. Indeed, the predictions of model 5 based on aphid-index are not significantly different from reality in two of the three statistical tests, contrary to the predictions of the models based on peak aphid density which are significantly biased. The analyses with the simulation model earlier in this paper have shown that in addition to the duration and the size of the aphid infestation, the shape of the infestation progress curve and the timing of the infestation are significant factors in determining damage. Taking these aspects of the infestation into account in the models 6 and 7 results in predictions which are not significantly different from reality.

The results of the analysis of the 'usefulness' of the regression models for predictive purposes differ from those of the analysis of the truthfulness of the models. Based on the median absolute value of the prediction error, model 5 is selected best (Table 7). Differences between the models are relatively small, the median absolute value of the prediction error of the majority of models differing less than $100 \mathrm{~kg} \mathrm{ha}^{-1}$ from the best. Confidence statements are not meaningful here in view of the relatively small and variable number of data sets used for model testing.

To illustrate the effect of the choice of a selection criterion on the selection result, the $75 \%$ quantile of the absolute value of the prediction error is also shown in Table 7. Based on the $75 \%$ quantile, model 3 is selected best. Thus, although the median absolute value of the prediction error of model 3 is larger than that of model 5 , the probability of large prediction errors is smaller. The risk attitude of the decision maker determines which quantile of the frequency distribution is most appropriate as selection criterion.

Besides the absolute value of the prediction error, other measures can be used to

Table 7. Statistical evaluation of the usefulness of seven regression models for cereal aphid damage in winter wheat, using $n$ datasets from the Netherlands. A description of the models is given in Table 3. The statistics shown are the median and the $75 \%$ quantile of the frequency distribution of the absolute value of the prediction error. Bold figures represent minimal values.

\begin{tabular}{llll}
\hline Model & $n$ & $\begin{array}{l}\text { median } \\
\left(\mathrm{kg} \mathrm{ha}^{-1}\right)\end{array}$ & $\begin{array}{l}75 \% \text { quantile } \\
\left(\mathrm{kg} \mathrm{ha}^{-1}\right)\end{array}$ \\
1 & 11 & 371 & 808 \\
2 & 21 & 193 & 423 \\
3 & 21 & 246 & 324 \\
4 & 232 & 331 \\
5 & 20 & 191 & 377 \\
6 & 20 & 260 & 430 \\
7 & 20 & 283 & 418 \\
\hline
\end{tabular}


express the accuracy of a model. These include, among others, the prediction error per se and the relative prediction error. Errors in the prediction of damage are of practical interest for supervised control only when they result in a wrong decision. Thus, when the predicted damage exceeds the cost of chemical control, a decision maker will be interested most in the error of overestimation by the model as this may result in a wrong decision (i.e. to spray). Similarly, when the predicted damage is smaller than the cost of chemical control, only the error of underestimation is relevant. A priori, however, over- and underestimation are equally undesirable, rendering the absolute value of the prediction error a more appropriate criterion than the prediction error per se. In supervised control, predicted damage is compared to the cost of control and the prediction error then represents a better measure of uncertainty than the relative prediction error.

Although care is taken to select independent data sets for model evaluation, no information is available on the data used for calibration of the models 2 and 3. As the performance of these models is evaluated with 21 data sets, 8 of which have been used in their development (Rabbinge and Mantel, 1981), some overestimation of the accuracy of these models is likely.

Selection of the best model has been carried out assuming the data sets used for testing of the models to be representative for situations in which the models are to be used. In the context of supervised chemical control the costs of the control operation determine to a large extent the range of damage which should be predicted with reasonable accuracy, low costs necessitating sufficiently accurate predictions of small damage only. The selection procedure should then be carried out using an appropriate subset of the 21 data sets available, omitting e.g. the sets where measured damage exceeds $1000 \mathrm{~kg} \mathrm{ha}^{-1}$.

\section{Conclusion}

Calculation of aphid damage at low attainable yield levels is preliminary as proper validation of the winter wheat $-S$. avenae simulation model was not yet possible due to lack of detailed experiments with aphid infestations at low levels of nitrogen input (Rossing, 1991).

Different simulated attainable yields have been obtained by initializing the crop growth model at flowering with data of field experiments carried out at different levels of nitrogen input. Conclusions on the effect of aphids may be different if variation in attainable yield is not caused by variation in nitrogen input but by variation in e.g. plant density due to wintering of the crop. Thus, attainable yield calculated in this study may differ from the concept of 'expected yield' in the advisory system EPIPRE, which is the farmer's grain yield estimate at the onset of the growing season (Drenth et al., 1989).

The calculations with the damage model for a range of crop-nitrogen conditions have shown that at crop development stages up to DC 73 aphid damage increases at an approximately constant rate with attainable yield level up to yield levels of ca 9000 $\mathrm{kg} \mathrm{ha}^{-1}$. At higher yield levels, the slope of the curve increases greatly. Aphid damage due to honeydew increases in proportion to leaf area index, whereas the contribution of additional leaf area index to crop yield decreases. As a consequence, damage per aphid-day is relatively large at high attainable yield levels as long as 
honeydew is the major cause of damage (up to DC 73). The second component of damage, aphid feeding, is approximately independent of yield level and becomes the major cause of damage after DC 73 when unsprayed aphid populations generally reach their peak density.

The results of the simulation model are summarized by exponential and logarithmic relations between damage per aphid-day and yield of an uninfested crop. No biological meaning should be attached to the structure of the regression models. Their only purpose is to summarize the information derived from the simulation model.

Evaluation of the agreement between the predictions of seven regression models for aphid damage and real world data using 21 independent data sets has shown the models which account for the duration and the size of the infestation (models 5 to 7) to be superior to the models which use peak aphid density to characterize the infestation (models 1 to 4 ) under both the F-test and Wilcoxon's signed rank test. The similarity in truthfulness of model 5 and models 6 and 7, respectively, indicates that the shape of the infestation progress curves and the timing of the infestations did not vary greatly between the data sets and was similar to the standard infestation used for constructing model 5 with the simulation model (Table 2).

Based on the median absolute value of the prediction error, model 5 has been selected the best. Although they are demonstrably biased, the single point models 2 , 3 and 4 may be more useful for decision making in supervised control systems than the multiple point models 6 and 7 due to the smaller median error in the predictions of the single point models.

Summarizing the output of the explanatory simulation model of the aphid - winter wheat system by means of regression analysis has yielded simple models which are as good as the best published empirical models in both truthfulness and usefulness. The advantage of the simulation approach in the development of these simple models over the strictly empirical approach followed for the other models is the explanatory nature of the simulation model which allows conclusions on the effect of grain aphid injury on winter wheat yield of a causal rather than a statistical nature.

\section{Acknowledgements}

The author wishes to thank Mr W.P. Mantel for kindly supplying the data used for evaluation of the regression models. The contribution of dr M.J.W. Jansen to the statistical aspects of this paper is greatly appreciated. Thanks are also due to prof. $\mathrm{dr}$ R. Rabbinge, dr W. van der Werf and prof. dr J.C. Zadoks for constructive criticism.

\section{References}

Anon., 1984. Proefveld te Helecine. Meetgegevens - groeiseizoen 1984. KU Leuven, SES, BDB, KBIVB.

Anon., 1985. Proefveld te Helecine. Meetgegevens - groeiseizoen 1985. KU Leuven, SES, BDB, KBIVB.

Carter, N., Dixon, A.F.G. \& Rabbinge, R., 1982. Cereal aphid populations: biology, simulation and prediction. Pudoc, Wageningen, $91 \mathrm{pp}$.

Drenth, H., Hoek, J., Daamen, R.A., Rossing, W.A.H., Stol, W. \& Wijnands, F.G., 1989. An evaluation of the crop-physiological and epidemiological information in EPIPRE. Bulletin EPPO / EPPO Bulletin 19: 417-424.

Neth. J. Pl. Path. 97 (1991) 
공 Appendix 1. Summary of data sets used for comparison of models for cereal aphid damage.

\begin{tabular}{|c|c|c|c|c|c|c|c|c|c|}
\hline \multirow{2}{*}{$\begin{array}{l}\text { Data } \\
\text { set }\end{array}$} & \multirow[t]{2}{*}{ Year } & \multirow[t]{2}{*}{ Location } & \multirow[t]{2}{*}{ Cultivar } & \multirow{2}{*}{$\begin{array}{l}\text { Control } \\
\text { yield } \\
\left(\mathrm{kg} \mathrm{ha}^{-1}\right)\end{array}$} & \multirow{2}{*}{$\begin{array}{l}\text { Infestation } \\
\text { period } \\
\text { (Decimal } \\
\text { code) }\end{array}$} & \multirow{2}{*}{$\begin{array}{l}\text { Peak } \\
\text { aphid } \\
\text { density } \\
\text { (tiller }^{-1} \text { ) }\end{array}$} & \multicolumn{2}{|c|}{ Infestation intensity } & \multirow{2}{*}{$\begin{array}{l}\text { Damage } \\
\left(\mathrm{kg} \mathrm{ha}^{-1}\right)\end{array}$} \\
\hline & & & & & & & (aphid-days) & $\begin{array}{l}\text { (aphid-unit } \\
\text { days) }\end{array}$ & \\
\hline 1. ${ }^{\mathrm{b}}$ & 1973 & Zonnewijnen & Manella & 6550 & $37-85$ & 1.22 & 29.8 & 16.3 & 130 \\
\hline $2 .^{b}$ & 1973 & Lienden & Manella & 3580 & $37-85$ & 2.41 & 29.9 & 15.6 & -420 \\
\hline $3 .^{b}$ & 1974 & Colijnsplaat & Lely & 8170 & $37-73$ & 0.77 & 13.8 & 6.8 & 100 \\
\hline $4 .^{b}$ & 1974 & Westmaas & Caribo & 6700 & $37-75$ & 3.92 & 50.1 & 25.3 & 160 \\
\hline $5 . b$ & 1975 & Colijnsplaat & Lely & 6150 & $41-79$ & 8.37 & 125.9 & 64.4 & 20 \\
\hline $6 .^{b}$ & 1975 & Herveld & Clement & 7360 & $45-79$ & 11.28 & 243.0 & 126.2 & 570 \\
\hline 7. ${ }^{b}$ & 1976 & Colijnsplaat & Lely & 6830 & $60-87$ & 27.45 & 500.8 & 279.8 & 360 \\
\hline $8 .^{b}$ & 1976 & Westmaas & Anouska & 5990 & $60-87$ & 14.28 & 219.7 & 119.8 & -90 \\
\hline 9. ${ }^{b}$ & 1976 & Wieringerwerf & Caribo & 7290 & $60-85$ & 35.32 & 418.1 & 229.5 & 670 \\
\hline $10 .^{b \cdot c}$ & 1977 & Lienden & Caribo & 5250 & $60-83$ & 14.92 & 241.5 & 130.2 & 100 \\
\hline 11. & 1978 & Lienden & Caribo & 5250 & $60-87$ & 8.69 & 226.7 & 127.5 & 490 \\
\hline 12. & 1978 & Westmaas & Arminda & 8040 & $58-77$ & 1.05 & 13.6 & 7.4 & 280 \\
\hline 13. & 1978 & Borgercompagnie & Okapi & 8100 & $65-85$ & 20.25 & 392.8 & 222.1 & 1090 \\
\hline 14. & 1979 & Westmaas & Donata & 6730 & $37-79$ & 64.03 & 1004.1 & 516.5 & 1890 \\
\hline 15. & 1979 & Wieringerwerf & Okapi & 7770 & $41-79$ & 37.91 & 608.6 & 326.5 & 930 \\
\hline 16. & 1979 & Borgercompagnie & Okapi & 6430 & $65-85$ & 1.50 & 20.3 & 11.5 & -160 \\
\hline 17. & 1979 & Rolde & Okapi & 5910 & $50-85$ & 3.00 & 45.7 & 26.3 & 100 \\
\hline 18. & 1979 & Emmercompascuum & Okapi & 6160 & $56-83$ & 0.50 & 5.4 & 3.1 & 360 \\
\hline 19. & 1979 & Randwijk & Arminda & 7220 & $68-89$ & 34.10 & 723.1 & 401.9 & 700 \\
\hline $20 .^{d}$ & 1984 & Nagele & Arminda & 10776 & $60-79$ & 44.35 & 544.4 & 295.7 & 1754 \\
\hline 21. & 1984 & Randwijk & Arminda & 10155 & $55-82$ & 15.83 & 194.7 & 106.6 & 238 \\
\hline
\end{tabular}

a Aphids treated with an insecticide on occurrance.

b b,c,d Data set not used for evaluation of damage models by Vereijken (1979), Entwistle \& Dixon (1987) and Rossing (this paper), respectively. 
Entwistle, J.C. \& Dixon, A.F.G., 1987. Short-term forecasting of wheat yield loss caused by the grain aphid (Sitobion avenae) in summer. Annals of Applied Biology 111: 489-508.

Gibbons, J.D., Olkin, I. \& Sobel, M., 1977. Selecting and ordering populations: a new statistical methodology. John Wiley, New York. 569 pp.

Groot, J.J.R., 1987. Simulation of nitrogen balance in a system of winter wheat and soil. Simulation Report CABO-TT nr. 13.69 pp.

Keulen, H. van \& Seligman, N.G., 1987. Simulation of water use, nitrogen nutrition and growth of a spring wheat crop. Pudoc, Wageningen. 310 pp.

Mantel, W.P., R. Rabbinge \& Sinke, J., 1982. Effekten van bladluizen op de opbrengst van wintertarwe. Gewasbescherming 13: 115-124.

Penning de Vries, F.W.T., 1977. Evaluation of simulation models in agriculture and biology: conclusions of a workshop. Agricultural Systems 2: 99-107.

Rabbinge, R. \& Mantel, W.P., 1981. Monitoring for cereal aphids in winter wheat. Netherlands Journal of Plant Pathology 87: 25-29.

Rabbinge, R., Sinke, C. \& Mantel, W.P., 1983. Yield loss due to cereal aphids and powdery mildew in winter wheat. Mededelingen van de Faculteit Landbouwwetenschappen Rijksuniversiteit Gent 48: 1159-1168.

Rabbinge, R., Ward, S.A. \& Laar, H.H. van, 1989. Simulation and systems management in crop protection. Pudoc, Wageningen. $420 \mathrm{pp}$.

Rautapää, J., 1966. The effect of the English grain aphid Macrosiphum avenae (F.) (Hom., Aphididae) on the yield and quality of wheat. Annales Agriculturae Fenniae 5: 334-341.

Rossing, W.A.H., 1991. Simulation of damage in winter wheat caused by the grain aphid Sitobion avenae. 2. Construction and evaluation of a simulation model. Netherlands Journal of Plant Pathology 97: 25-54.

Rossing, W.A.H. \& Wiel, L.A.J.M. van de, 1990. Simulation of damage in winter wheat caused by the grain aphid Sitobion avenae. 1. Quantification of the effects of honeydew on gas exchange of leaves and aphid populations of different size on crop growth. Netherlands Journal of Plant Pathology 96: 343-364.

SAS, 1985. SAS User's Guide: Statistics. Version 5 Edition. Cary, N.C. SAS Institute Inc. 956 pp.

Snedecor, G.W. \& Cochran, W.G., 1980. Statistical methods. Iowa State University Press, Ames, lowa. 7 th edition. $507 \mathrm{pp}$.

Vereijken, P.H., 1979. Feeding and multiplication of three aphid species and their effect on yield of winter wheat. Agricultural Research Reports 888. Pudoc, Wageningen. 58 pp.

Wit, C.T. de \& Goudriaan, J., 1978. Simulation of ecological processes. Pudoc, Wageningen. $183 \mathrm{pp}$.

Wratten, S.D., Lee, G. \& Stevens, D.J., 1979. Duration of cereal aphid populations and the effects on wheat yield and quality. Proceedings 1979 British Crop Protection Conference Pests and Diseases 1: 1-8.

Zadoks, J.C., Chang, T.T. \& Konzak, C.F., 1974. A decimal code for the growth stages of cereals. Eucarpia Bulletin 7: 42-52.

Zadoks, J.C. \& Schein, R.D., 1979. Epidemiology and plant disease management. Oxford University Press, New York. 427 pp.

Neth. J. Pl. Path. 97 (1991) 